\title{
Subluxation Injury in Primary Teeth: A Case Report
}

\author{
Rameshwari Raol $^{1 *}$, Parth Joshi ${ }^{1}$, Yasheshvini Raol ${ }^{2}$ and Monika Khoja ${ }^{1}$ \\ ${ }^{1}$ MDS in Pedodontics and Preventive Dentistry, Adhyamaheshwar Dental Clinic, India \\ ${ }^{2}$ Undergraduate, College of Dental Sciences and Hospital, Amargadh, India
}

*Corresponding author: Rameshwari Raol, MDS in Pedodontics and Preventive Dentistry, Adhyamaheshwar Dental Clinic, India

\begin{abstract}
Subluxation, also called central dislocation, is often the result of an axial impact in the apical direction, moving the tooth within the alveolar bone. This is perhaps one of the most traumatic injuries, since the displacement of a tooth within its socket implies extensive and acute involvement of the periodontal ligament, bone damage and rupture of the neurovascular bundle. The close relationship between the apexes of the primary teeth and the developing permanent successor in turn can lead to multiple complications, which are greater when the permanent tooth is affected in the early stages of development.
\end{abstract}

Keywords: Subluxation; Dental Trauma; Primary Teeth

\section{Introduction}

Trauma to the oral hard and soft tissues is commonly seen in children. Among all facial injuries, dental injuries are the most common. As much as $18 \%$ of all injuries in children up to 6 years of age are seen in the oral region [1]. Injuries to the primary dentition are common, occurring with a significantly higher annual incidence than in the permanent dentition [2]. One third of all children in the primary dentition stage suffer from traumatic injuries to the mouth. This is possibly related to poor motor coordination and is sometimes due to the child's inability to evaluate risks [3]. Resilience of the alveolar bone in young children causes dental luxations of the intrusive type to be more common than crown fractures [4-6]. Traumatic injuries to the primary dentition are often overlooked by parents mainly because less attention is given to the primary dentition and to the child's inability to cope with the situation.

\section{Case Report}

A male patient of 6 years old reported to the dental hospital along with his parents. The chief complaint of the patient was pain in upper anterior teeth. His height was $4 \mathrm{ft} .8$ inch and weighed $32 \mathrm{~kg}$. No relevant medical history was recorded. Family medical history was also not significant. It was his first dental visit. No other oral habits were present. On further questioning patient gave history of brushing by self once a day with adult size toothbrush using fluoridated toothpaste. He was well built, and his gait was normal with straight posture and mesomorphic body type. His facial profile was convex with competent lips.eth traumatized. On functional examination patient had nasal breathing and adult type of swallow pattern. He had 24 teeth present in his oral cavity. The parents informed that the child fell from a bicycle and got his teeth traumatized. On intra oral examination of the maxillary arch, the central incisors were found to be tender and mobile (Figure 1). Radiograph was recorded and it showed more than $50 \%$ root resorption of primary central incisors in the maxillary arch (Figure 2). Also, the soft tissue around 51 and 61 was swollen due to the injury. Hence, the diagnosis of subluxation was made.

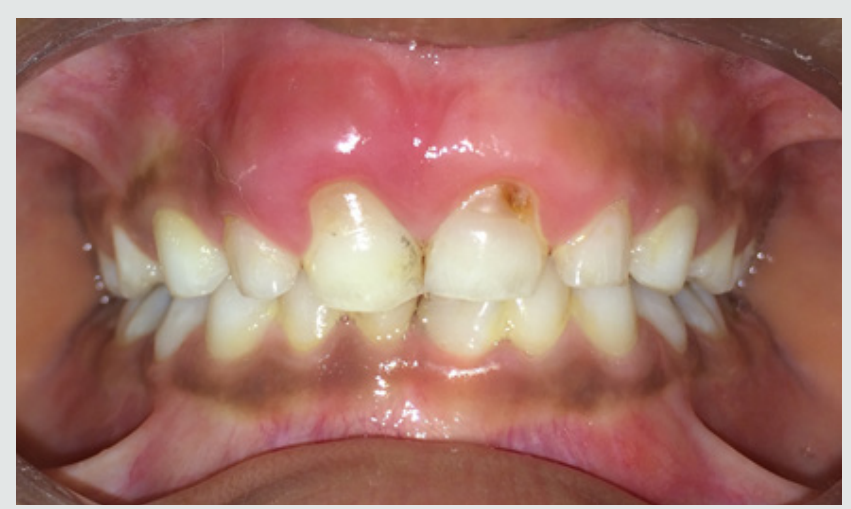

Figure 1: 


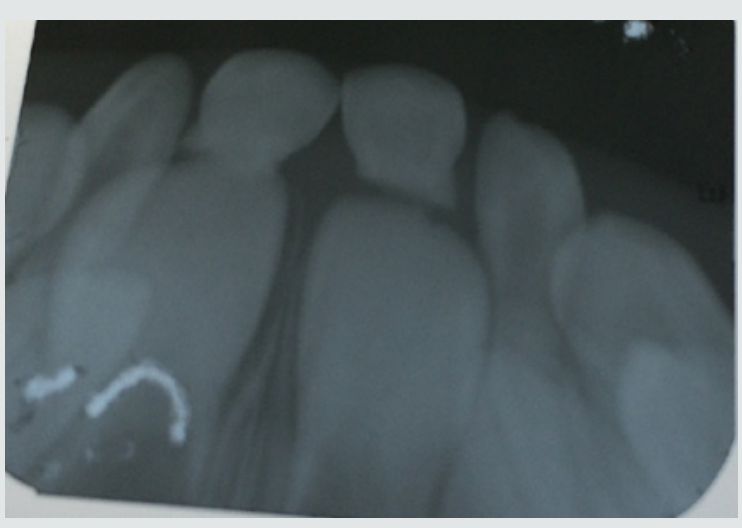

Figure 2:

\section{Treatment Regimens}

The overall principle of treatment is not to take any risk of damage to the permanent successor, which usually implies a very conservative approach. Use of topical anesthetics, local anesthesia, and sedation should be considered. Analgesics may improve the quality of care when pain is anticipated. The administration of a single dose of analgesic $1 \mathrm{~h}$ before injection and the use of a topical anesthetic will reduce the discomfort of a local anesthetic [7]. Adequate oral hygiene and a soft diet should be prescribed. Management of an intruded primary incisor depends on the following variables:

a) Direction of intrusion.

b) Degree of intrusion.

c) Presence of alveolar bone fracture.

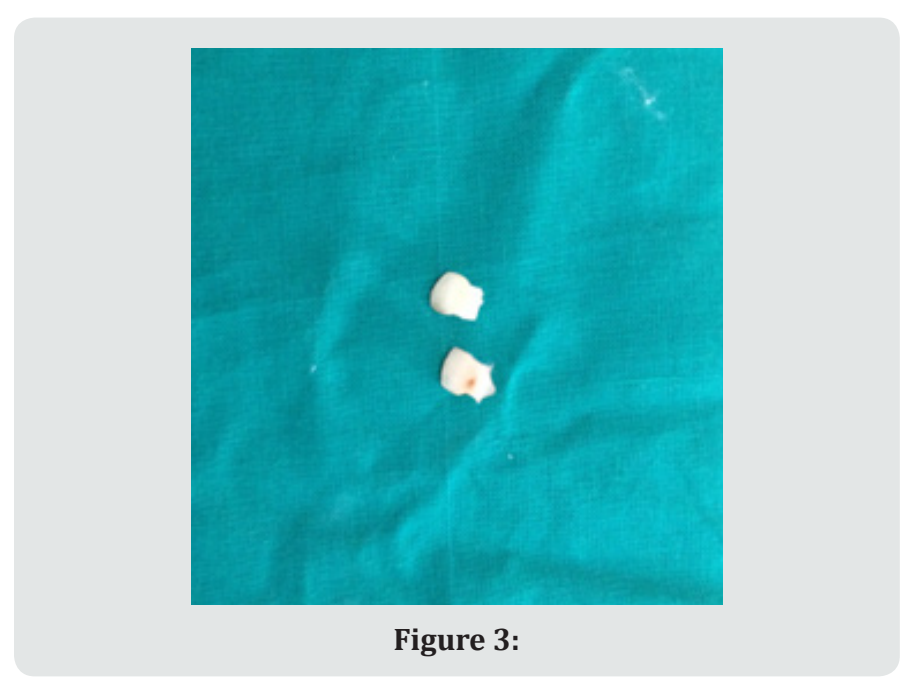

For the present case we did the extraction of 51 and 61 as already there was resorption of them (Figure 3). Extraction was done using local anesthesia. The soft tissues were cleansed and irrigated with betadine solution. The patient was recalled every 3 months for regular follow up until the permanent incisors were erupted in normal condition (Figure 4).

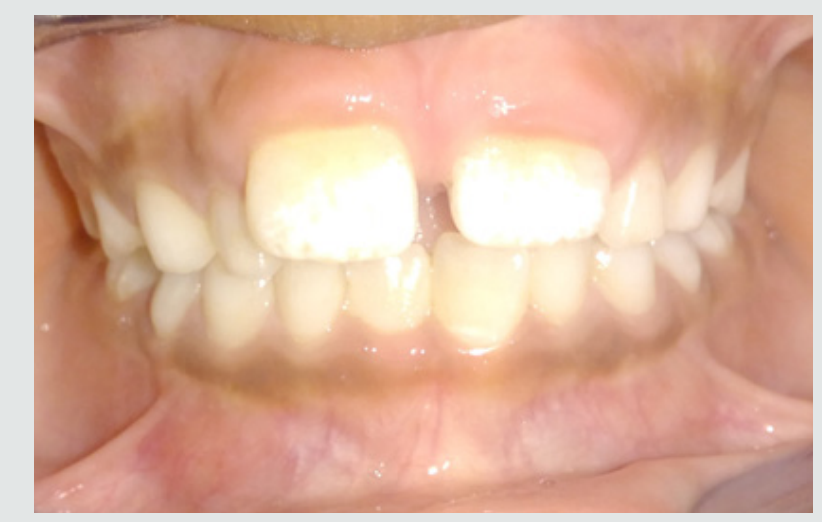

Figure 4:

\section{Discussion}

Injury to the child patient is a traumatic experience on a physical as well as emotional and psychological level. In view of the patient's tender age and the likelihood that the dental visit will be the patient's first, managing the child's traumatic injuries is a demanding task. The close relationship between the apex of the injured primary tooth and the underlying permanent tooth germ must be kept in mind. In the present case, we extracted the tooth and gave post extraction instructions. Antibiotic therapy was prescribed to prevent the spread of inflammation to the permanent tooth germ, as advocated by Kenny and Yacobi , Andreasen and Andreasen [3], Wilson [8], and Andreasen et al. [9]. After extraction, the irregularity of the resorbed root surface was evident, postextraction intra-orally. It was due to external inflammatory root resorption, confirming the radiographic diagnosis [10-15].

\section{Conclusion}

Special care should be taken during the evaluation and followup of traumatized immature teeth. The long-term prognosis of immature teeth is dependent on continued root formation. In cases of subluxation of primary teeth, it is essential to diagnose the direction of the displaced tooth to rule out injury to the successor and thus prevent the occurrence of sequelae in the permanent dentition. Regular follow up should be mandatory to observe the successors [15-18].

\section{References}

1. Flores MT, Malmgren B, Andersson L, Andreasen JO, Bakland LK, et al. (2007) Guidelines for the management of traumatic dental injuries. III. Primary teeth. Dent. Traumatol 23: 196-202.

2. Diab M, El Badrawy HE, (2000) Intrusion injuries of primary incisors. Part 1: Review and management. Quintessence Int 31: 327-334.

3. Borum MK, Andreasen JO (1998) Sequelae of trauma to primary maxillary incisors. I. Complications in the primary dentition. Endod Dent Traumatol 14: 31-34.

4. Bennett DT (1964) Traumatized anterior teeth. Br Dent J 116: 52- 55.

5. Ferguson FS, Ripa LW (1979) Prevalence and type of traumatic injuries to the anterior teeth of preschool children. J Pedod 3: 3-8. 
6. Croll TP, Brooks EB, Schut L, Laurent JP (1980) Rapid neurological assessment and initial management for the patient with traumatic dental injuries. J Am Dent Assoc 100: 530-534.

7. Borum MK, Andreasen JO (2001) Therapeutic and economic implications of traumatic dental injuries in Denmark: an estimate based on 7549 patients treated at a major trauma centre. Int J Pediatr Dent 11: 249-258.

8. Fried I, Erickson P (1995) Anterior tooth trauma in the primary dentition: Incidence, classification, treatment methods and sequelae. A review of literature. J Dent Child 62: 256-261.

9. Andreasen JO (1970) Etiology and pathogenesis of traumatic dental injuries. A clinical study of 1298 cases. Scand. J Dent Res 78: 329-342.

10. Altun C (2009) Traumatic intrusion of primary teeth and its effects on the permanent successors: a clinical follow-up study. Oral Surg Oral Med Oral Pathol Oral Radiol Endod 107(4): 493-498.

11. American Academy of Pediatric Dentistry (2010-2011) Guidelines on management of acute dental trauma. Reference Manual 32(6): 202-212.

12. Avdin MY, Kargul B (2004) Glass-fibre reinforced composite in management of avulsed central incisor: a case report. J Dent Child 71(1): 66-68.
13. Bijella MFT (1990) Occurrence of primary incisor traumatism in Brazilian children: A house-by-house survey. J Dent Child 57: 424-427.

14. Borum MK, Andreasen JO (1998) Sequelae of trauma to primary maxillary incisors. I. Complications in the primary dentition. Endod Dent Traumatol 14: 31-34

15. Crespi PV (1992) Intrusive injuries to the dentition. NY State Dent J 62 35-38.

16. Cunha RF (2001) Early treatment of an intruded primary tooth: a case report. J Clin Pediatr Dent 25 (3): 199-202.

17. Flores MT (2002) Traumatic injuries in the primary dentition. Dent Traumatol 18: 287-298.

18. Galea H (1984) An investigation of dental injuries treated in an acute care general hospital. J Am Dent Assoc 109: 434-438.

19. Garcia Godoy F, Garcia Godoy F, Garcia Godoy FM (1987) Primary teeth traumatic injuries at a private pediatric dental center. Endod. Dent Traumatol 3: 126-129.

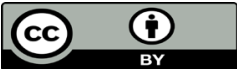

This work is licensed under Creative Commons Attribution 4.0 License

To Submit Your Article Click Here:

Submit Article

DOI: $10.32474 /$ IPDOAJ.2019.03.000159

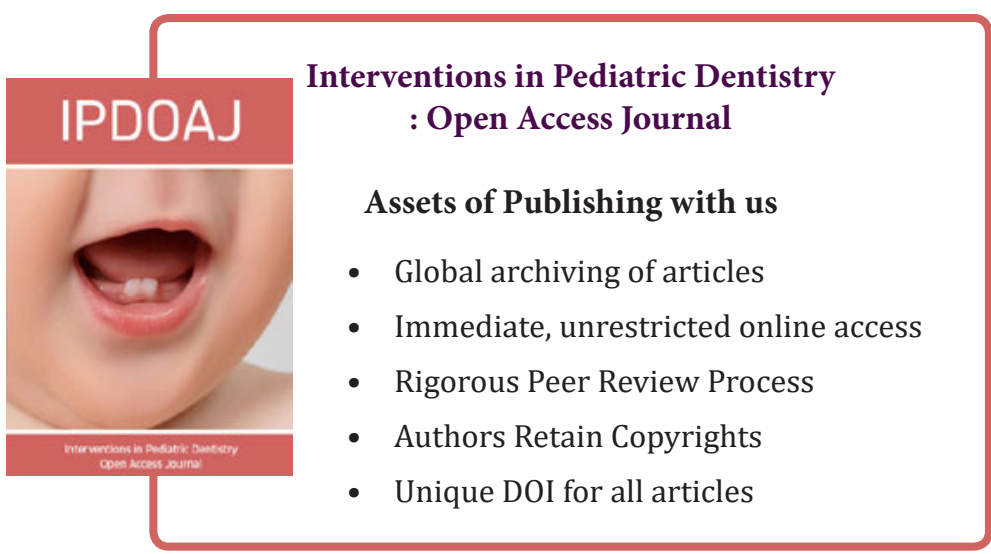

